\title{
RECONTEXTUALIZAÇÕES DO -ISMO: Disputas em torno do jornalismo "em crise"
}

\section{RECONTEXTUALIZATION OF THE -ISM: Disputes around an "in crisis" journalism}

\author{
Nuno Manna \\ Doutor em Comunicação Social pela Universidade Federal de Minas Gerais (UFMG), professor adjunto na Faculdade de \\ Comunicação da Universidade Federal da Bahia (UFBA). \\ <nunomanna@gmail.com>
}

\section{Phellipy Jácome}

Doutor pelo PPGCom da Universidade Federal de Minas Gerais (UFMG) e membro do Núcleo de Pesquisa Tramas Comunicacionais.

<phellipyjacome@gmail.com>

\section{Thiago Ferreira}

Doutorando, bolsista Capes, membro do Centro de Pesquisa em Estudos Culturais e Transformações na Comunicação (TRACC/ Póscom-UFBA).

<thiagoemanoel87@gmail.com>

\section{RESUMO}

Este artigo tem por objetivo problematizar, através de um exercício historicizante, a ideia de uma "crise" do jornalismo diagnosticada por vários autores e agentes midiáticos contemporâneos. Para tanto, nos dedicamos a compreender e a inquerir uma série de discursos autorreferentes buscando, num primeiro momento, traçar as características desse "contexto de crise". Como perceberemos, elas partem de um regime de crenças moderno que, sob a tutela de um -ismo, almeja delimitar as fronteiras do exercício jornalístico, a partir de um conjunto de valores, institucionalidades, que estariam, agora, sofrendo uma série de questionamentos e reiterações. Em seguida, analisamos algumas das respostas - advindas de mídias de "referência" e "alternativas" - que nos permitem perceber que concepções de jornalismo são atualizadas nesse contexto, e de que maneira diferentes agentes da mídia informativa reivindicam um lugar nessa recontextualização.

\section{ABSTRACT}

This article aims to problematize, through a historicizing exercise, the idea of "journalism's crisis" diagnosed by various contemporary authors and media agents. In order to do so, we are dedicated to comprehend and to inquire a series of self-referential discourses seeking, in a first moment, to outline the characteristics of this context of crisis. As we shall see, they depart from a modern belief system which, under the tutelage of a -ism, seeks to delimit the frontiers of journalistic exercise, based on a set of values, institutions, which would now face a series of questions and reiterations. Finally, we analyze some of the answers - coming from "reference" and "alternative" media - that allow us to understand which conceptions of journalism are updated in this context, and how different agents of news media claim a place in this recontextualization.

Keywords: Journalism.Crisis.Context.

\section{Apresentação}

Este trabalho dedica-se a compreender e a problematizar, a partir de uma variedade de discursos autorreferentes, o contexto de intensas transformações 
no cenário midiático avaliadas por distintos autores, profissionais e corporações midiáticas como uma "crise do jornalismo". Diante desse diagnóstico da "crise", diferentes agentes jornalísticos vêm respondendo não apenas com atualizações de seus formatos e planos de negócio, mas com protocolos de revisão e afirmação de seus valores e de suas fronteiras institucionais. O que pretendemos, portanto, é analisar algumas dessas "respostas" a partir de uma perspectiva historicizante, que nos permita perceber que concepções de jornalismo são atualizadas nesse contexto, e de que maneira diferentes agentes da mídia informativa reivindicam um lugar nessa recontextualização.

De maneira geral, é possível perceber que, profundamente afetados e ameaçados pelas transformações no campo midiático, grandes empresas de comunicação vêm lutando pela manutenção de um lugar privilegiado do jornalismo dito "de referência". Por outro, novas práticas e novos agentes vêm tensionar a hegemonia dos grandes jornais, e reivindicar lugares de legitimidade no campo jornalístico. Tais empreendimentos vêm conformando um cenário de disputas que certamente passam por dimensões de mercado e público, mas que, institucionalmente, se iniciam na própria maneira de compreender e legitimar o jornalismo do qual se postulam como os verdadeiros representantes.

Tomando tal contexto como mobilizador de discursos que constituem a historicidade do jornalismo no Brasil e como oportunidade de reflexão sobre os valores estruturantes de uma matriz jornalística, buscamos aqui compreender o jornalismo, ele próprio, como campo de conflitos culturais. Tal matriz, como veremos, é fortemente devedora de uma concepção de "jornalismo moderno" e daquilo que se costumou chamar de "modelo americano de jornalismo" (Lage, Faria, Rodrigues, 2004; Abreu, 2002; Jobim,1954). Além disso, ela encontra em nossa análise um lugar de afirmação em meio aos processos históricos de institucionalização do jornalismo como campo profissional e epistemologicamente autônomo, institucionalidade sintetizada na própria emergência do sufixo -ismo (Nerone, 2009, 2013) como lugar de legitimação.

Nesse sentido, em um primeiro momento, partimos de uma breve caracterização do diagnóstico da crise como forma de apreensão e de consequente crítica dos valores e concepções históricas que ele supõe. Tal movimento nos permite aprofundar a percepção contextual do jornalismo, na medida em que, ao recuperarmos aspectos do seu passado, o -ismo se revela concretamente como uma emergência histórica - e, como tal, muito mais descontínuo, ambíguo e heterogêneo do que o discurso da crise faz parecer.

Em seguida, buscamos em alguns exemplos recentes de enunciados promovidos por agentes midiáticos as marcas de uma busca por atualização 
de uma matriz jornalística na qual configuram formas distintas de inserção: em primeiro lugar, encontramos traços autolegitimadores de jornais que compõem o que, nesta matriz, se toma comumente como um jornalismo "de referência" periódicos tais como O Globo e Folha de S. Paulo; em segundo, tomamos algumas expressões de manifestações midiáticas que, de certa forma, vêm se oferecendo em contraposição a tal parcela da imprensa, pelo que vem sendo chamado de "jornalismo alternativo" -como a Mídia Ninja e os Jornalistas Livres.

Nesses movimentos, buscamos mobilizar uma noção de contexto cara aos estudos culturais, mais propriamente a Lawrence Grossberg (2010), que nos orienta menos como um conceito do que como um desafio de abordagem dos fenômenos históricos. Como afirma o autor, nenhum elemento pode ser isolado de seus contextos, embora estes possam ser modificados, e estejam constantemente mudando. "Qualquer evento só pode ser compreendido relacionalmente, como uma condensação de determinações e efeitos múltiplos" (Grossberg, 2010, p. 20, tradução nossa)'1. Desse modo, buscamos compreender como certos fenômenos jornalísticos contemporâneos atuam, no contexto de "crise", não simplesmente para a reafirmação ou o questionamento de uma matriz jornalística, mas para a atualização do próprio -ismo como um complexo e ambíguo lugar de disputas por hegemonia.

\section{A "crise" dos jornais e a atualização do -ismo}

Nas últimas décadas, diversos estudiosos do jornalismo vêm se dedicado a mapear transformações estruturantes do campo (Zelizer, 2008 e 2009; Sant'Anna, 2008; Anderson, Belle, Shirky, 2013; entre outros). Entre elas, são destacadas mudanças de caráter "qualitativo", como a crescente "tabloidização" da imprensa e o enfraquecimento de valores consagrados da regulação profissional jornalística, e outras de caráter "quantitativo", como a queda de tiragem de jornais impressos e da popularidade de telejornais, o abalo financeiro do mercado jornalístico com o consequente corte de quadros profissionais, a redução da receita de empresas jornalísticas e mesmo a descontinuação de publicações tradicionais.

Durante muito tempo, acreditou-se que se tratava ("apenas") de uma crise do jornal diário impresso, mídia que mais insiste em certos padrões tradicionais de jornalismo e que mais resistia às adaptações diante dos novos tempos. Em 2008, o jornalista Ricardo Noblat, por exemplo, tecia em seu livro um conjunto

1 Do original: Any event can only be understood relationally, as a condensation of multiple determinations and effects (Grossberg, 2010, p. 20). 
de críticas e de sugestões à prática jornalística tomando a crise dos jornais impressos como dado:

É feia a crise. Estou convencido de que donos de jornal e jornalistas compartilham o firme propósito de acabar com os jornais. [...] Os donos porque administram mal as empresas; os jornalistas porque insistem com um modelo de jornal que desagrada às pessoas (NOBLAT, 2008, p.13-14).

Outro interessante exemplo foi a retomada de uma fala de Alberto Dines jornalista que, entre outras coisas, foi um dos responsáveis pela famosa reforma do Jornal do Brasil(JB) nos anos 1960 - que em 1974 escreveu em O papel do jornal:

\footnotetext{
Um retrospecto da história do jornal, desde o seu surgimento em 1605 , revela que ele resistiu, assim como o livro, a todos os embates da tecnologia e das mudanças sociais. O obscurantismo político, a revolução industrial, as invenções para vencer as distâncias, as guerras, as migrações, a recessão econômica, a TV, tudo, enfim, foi absorvido pelo veículo mais institucionalizado de todos, o jornal diário. (DINES, 1974, p. 78, grifos nossos)
}

Os dizeres de Dines foram recuperados em 2015 - poucos anos após o fim da circulação impressa do $J B$ - por um texto do jornalista Jota Alcides no site do Observatório da Imprensa, com título homônimo ao livro referido. Alcides atualiza a discussão da função da imprensa, tendo em vista o abalo institucional do jornal diário, afirmando que "está em curso a maior crise dos jornais no mundo em mais de 400 anos de história" (Alcides, 2015).

Entre acadêmicos, muitos também se demonstraram preocupados com o futuro do jornalismo (Almiron, 2010; Fuller, 2010; Schlesinger, 2006; Starr, 2012; Young, 2010; entre outros), fossem otimistas ou pessimistas em suas apostas. E, como sugerem as análises mais estruturais do lugar do jornalismo na cultura contemporânea, logo se percebeu que a fragilidade do diário impresso apontava para tudo aquilo que ele, aparentemente mais do que qualquer outra modalidade de jornalismo, representa.

Em artigo publicado em 2002 também no Observatório da Imprensa intitulado "Crise nos paradigmas do jornalismo", Luiz Gonzaga Motta observava uma movimentação teórica em torno do estado dos estudos em jornalismo, um sintoma das intensas mudanças que vinham fazendo com que o jornalismo fosse repensado enquanto objeto de estudo. Isso porque, para o autor, um 
paradigma hegemônico, que reivindica a linguagem é uma cópia do real, vem se mostrando cada vez mais insuficiente para oferecer parâmetros teóricos às práticas do jornalismo:

Os fatos, diz o paradigma, devem falar por si mesmos. Existe um realismo ingênuo e um realismo crítico, que não confia apenas na experiência, mas também na razão e no método, posição evidentemente mais comum hoje em dia nos círculos funcionalistas. Os fundamentos de ambos estão, entretanto, na mesma convicção de que a realidade existe independentemente de quem a observa e o jornalista, por uma atitude imparcial, é capaz de observar a realidade de forma neutra, sem julgamentos prévios, sendo capaz de transcrevê-los de forma objetiva, sem contaminar-se com opiniões (Motta, 2002).

O que Motta observa em curso não é necessariamente o questionamento de tal paradigma, mas o contrário disso. Segundo ele, em geral, por mais que a prática jornalística tenha passado por mudanças em suas rotinas, ela continua operando por uma mesma retórica. Além disso, a crença na primazia dos fatos foi reforçada com o advento do jornalismo on-line, que teria sacramentado o discurso da objetividade, da síntese e da imediaticidade com sua linguagem telegráfica. O jornalismo impresso tampouco teria feito qualquer ruptura radical nas repetidas maneiras de produzir a notícia. "Ao contrário, fizeram mais uma readaptação legitimadora de suas rotinas e linguagens para fazer frente às exigências da instantaneidade e da visualidade, em prejuízo da palavra" (Motta, 2002). Não existiria, nesse sentido, um rompimento epistemológico nas novas práticas jornalísticas. Um exemplo disso é a atualização de vocábulos associados a essa normatividade como possíveis respostas a essa crise. Afinal, imparcialidade, independência, neutralidade, isenção etc. frequentemente surgem para substituir o significante objetividade, sem que haja qualquer problematização do seu significado. Esse mesmo diagnóstico da crise de um certo "paradigma clássico" e a proposta de sua "solução" pela substituição dessas palavras podem ser encontradas também em autores como Dahlgren (2009, 2010) e Gillmor (2005).

Desse modo, se há uma importante crítica a ser levada em conta em tal diagnóstico, por outro lado devemos observar que a caracterização de tal contexto em termos de "crise"negligencia uma série de problemas e contradições inerentes aos processos históricos que fundam uma matriz cultural do jornalismo dominante e da própria noção de crise a ele associada. Tal caracterização acaba circunscrevendo o jornalismo dentro de um quadro estável, homogêneo e 
fundamentalmente não problemático, que cria as condições de compreensão de uma crise e, consequentemente, da necessidade de sua superação.

É nesse sentido que a lógica "mudar para permanecer o mesmo" tem sido uma constante ao longo da história do jornalismo brasileiro, sobretudo a partir de sua chamada "modernização" dos anos 1950 (Jácome, Leal, Manna, 2017). A partir daí, e de forma mais evidente em diversos discursos autorreferentes de distintas mídias, é possível perceber a configuração de uma narrativa persistente e circular na afirmação exaustiva daqueles que seriam os seus valores "essenciais". Entre eles, é possível destacar o compromisso com a objetividade, a independência e a imparcialidade, o que fixa normativamente o jornalismo como uma disciplina da verificação (Kovach,Rosenstiel, 2004), tendo a notícia ou a informação como o resultado de um minucioso trabalho de apuração, baseado em técnicas específicas de investigação e de composição textual. Como consequência, essa "essencialização" tende a apontar para uma história linear, monumental, atribuída a um único plano temporal possível que, por consequência, desistoriciza uma série de relações ao tomá-las como estáticas. Entretanto, a própria formulação modernae normativa do jornalismo possui uma história, que deveria ser mais questionada.

Nesse sentido, parece um consenso historiográfico que esse discurso moderno do jornalismo se confunde com um certo tipo de reconfiguração das práticas jornalísticas próprias dos Estados Unidos. Kaplan $(2002,2010)$, por exemplo, afirma que durante mais de um século, a imprensa estadunidense abraçou a objetividade como definidora de sua missão pública, e que esse código profissional que advoga pela imparcialidade e por uma factualidade rigorosa tem sido celebrado como o logro mais orgulhoso e difícil de sustentar do jornalismo daquele país.

De maneira similar, Jay Rosen (2003) afirma que a objetividade é uma das principais marcas identificadores do jornalismo estadunidense e talvez tenha sido a maior influência daquele país para um certo modo de compreensão das práticas jornalísticas em todo o mundo. Também Schudson $(2001,2010)$ advoga que a objetividade está na base do processo de profissionalização do jornalismo nos EUA e que pode ser considerado como uma espécie de "excepcionalidade americana", tornada possível por uma sociedade cujas bases não teriam sido assentadas através de grandes dissensos. Outros autores como Schiller (1981), Chalaby (1996) também caracterizam o jornalismo estadunidense a partir de uma "base objetiva" como sua grande influência para as práticas jornalísticas ao redor do globo.

É nessa perspectiva que, como sustenta Nerone $(2009,2013)$, o jornalismo se constitui como -ismo, na medida em que ele é um sistema de crenças. Dito 
sistema define quais seriam as práticas e valores apropriados tanto para os profissionais da notícia, quanto para as mídias, marcando uma diferenciação entre "jornais" e "jornalismo". Para exemplificar a diferença entre os termos, Nerone afirma que o jornalismo busca distinguir as notícias que repousam sobre sua disciplina de outras formas noticiosas. "Na era moderna, por exemplo, o jornalismo tem designado seus 'outros' de várias formas como fofoca, tabloides, sensacionalismo, partidarismo e assim por diante. Ele não nega que se trate de práticas noticiosas, mas questiona se seriam mesmo jornalismo"' (Nerone, 2013, p.2, tradução nossa).

O que temos aí, portanto, é uma clara diferenciação entre as práticas que comporiam esse -ismo (associadas a uma série de valores como objetividade, independência e imparcialidade), e outras, descompromissadas, que surgem como o seu "outro" indesejável. Essa normatividade moderna, apesar de possuir raízes nos Estados Unidos verificáveis na passagem do século XIX ao XX, acabou por gestar uma reflexão hegemônica sobre o jornalismo, remodelada em diferentes países (Nerone, 2013) e persistentes até hoje.

No caso brasileiro, a adoção desse -ismo é um fenômeno complexo que começa a ser fomentado no final dos anos 1920 e consolida-se com muito mais força a partir dos anos 1940 e 1950 (Albuquerque, 2010; Ribeiro, 2007). É dessa época a autonomização do campo jornalístico em relação a outros domínios e práticas, o que incluiu uma série de discursos autorreferentes e normativos que visavam estabelecer tanto uma diferença entre jornalismo e literatura, por exemplo. Encarados como movimentos de "modernização" do jornalismo brasileiro, essa série de transformações acabou por unificar as demandas e padronizar aquilo que, normativamente, deveria ser entendido como jornalismo em nosso país. Nesse período, várias reformas dos periódicos brasileiros culminavam numa retórica comum desse novo -ismo. Assim, segundo Ribeiro (2007, p.13), as "reformas redacionais, gráficas e editoriais do Diário Carioca em 1950 e do Jornal do Brasil em 1956, assim como o surgimento de jornais inovadores como a Tribuna da Imprensa em 1949 e a Última Hora em 1951 " são frequentemente descritos como marcos inaugurais de uma nova fase da imprensa brasileira.

Tendo isso em mente, acreditamos ser possível perceber aspectos da contextualidade dos discursos da crise por meio da concepção de MartínBarbero (2008) em torno das matrizes culturais. Isso significa que podemos compreender diacronicamente as práticas, formatos e discursos recentes em

2 Do original: In the modern era, for instance, journalism has designated its 'other' in various ways as gossip, tabloid news, sensationalism, partisanism, and so forth. It does not deny that these are news practices, but it does question whether these are journalism (Nerone, 2013, p. 2). 
torno do jornalismo a partir dos processos históricos de modernização da imprensa, que constituíram culturalmente o -ismo como um lugar forte de uma matriz jornalística. Significa ainda, a partir de Gomes e outros (2016), que podemos compreender as matrizes da mídia não como"algopré ou a-midiático", mas sim, pensadas como "matrizes culturais conformadas no próprio campo midiático" (Gomes e outros, 2016, p. 223).

Além disso, nos detemos na mediação da institucionalidade (MartínBarbero, 2008), configurada na relação que se estabelece entre essas matrizes e lógicas de produção do jornalismo. Ou seja, para além do aspecto de controle, a partir das formulações dominante-hegemônicas que configuram o ismo, observamos aqui as disputas e reiterações que se articulam aos valores do jornalismo dito moderno.

\section{Tradicional jornalismo moderno}

Como apontam estudiosos da história da imprensa no Brasil (Albuquerque, 2010; Albuquerque, Gagliardi, 2011; Barbosa, 2007; Ribeiro, 2007), um discurso base da modernização sustenta que um pequeno grupo de indivíduos foi capaz de transformar radicalmente a prática jornalística no país, na medida em que introduziu uma série de mudanças técnicas, bem como foi capaz de alavancar a profissionalização e institucionalização deste campo. Assim, de um jornalismo doutrinário, partidário e literário, teríamos subitamente passado a outro, profissional, imparcial e objetivo. Nesse discurso, podemos perceber uma ressemantização do jornalismo a partir de uma normatividade que busca padronizar as formas pelas quais os fatos deveriam ser apurados, escritos e apresentados.

Como um índice disruptor desse processo amplo, podemos analisar uma série de recomendações aos jovens jornalistas realizadas pelo Diário Carioca na década de 1940, reunidas sob o título de Cartas a um foca. Lançado em agosto de 1945, a coluna era assinada pelo nome fictício de "Joaquim Manoel", codinome atribuído ao jornalista Pompeu de Sousa (Ribeiro, 2007, p.33). Publicada ao longo de seis dias $(4,7,8,9,10$ e 11 de agosto), a seção sempre trazia uma mesma advertência destacada "Numa terra em que todos se julgam jornalistas, eis uma pequena seção para discutir todos os dias os assuntos do jornalismo". Um dos objetivos centrais era, então, diferenciar e elevar a atividade exercida pelos jornalistas através da disseminação de certos conhecimentos técnicos e procedimentos textuais.

Assim sendo, as colunas tratam de explicar, a partir da adaptação de manuais de redaçãoestadunidenses, da leitura de diários estrangeiros e exemplos próprios, quais seriam as normas de escrita jornalística adequadas ao 
jornalismo moderno. É, portanto, um momento de formação e de consolidação da identidade profissional moderna, na qual o jornalista começa a ser valorizado como um sujeito dotado de técnicas que lhe permitiriam apurar as notícias da maneira mais objetiva. Ao dizer que no Brasil, "todos se julgam jornalistas", o que se pretende é, então, separar aqueles que, efetivamente, deveriam ser considerados como tal. Todo o esforço aí se dá, portanto, no sentido de uma formação de identidades profissionais com a delimitação de suas fronteiras.

Com argumentos similares, mas posicionamentos diferentes, frutos de um novo contexto histórico é que podemos interpretar os Princípios Editoriais do Grupo Globo. Lançado em 2010, ele parece ser uma tentativa já não mais de uma formação, mas sim de manutenção dessa segregação entre jornais e jornalismo. Se o esforço do Diário Carioca pode ser entendido no sentido de separar jornalistas de literatos, criando um campo discursivo próprio, no caso do Grupo Globo, é como se esse campo já constituído estivesse agora ameaçado pela emergência de novos agentes. Por isso, já na introdução da sua carta de intenções, o grupo deixa claro que, na era digital,

(...) nota-se certa confusão entre o que é ou não jornalismo, quem é ou não jornalista, como se deve ou não proceder quando se tem em mente produzir informação de qualidade. (...) Ao mesmo tempo, porém, ela obriga a que todas as empresas que se dedicam a fazer jornalismo expressem de maneira formal os princípios que seguem cotidianamente. O objetivo é não somente diferenciar-se, mas facilitar o julgamento do público sobre o trabalho dos veículos, permitindo, de forma transparente, que qualquer um verifique se a prática é condizente com a crença (Grupo Globo, 2010).

No trecho acima, podemos perceber todo um esforço na manutenção da divisão proposta em Cartas a um foca e que marca esse discurso da modernização. Nele, há uma constante convocação ao protocolo de formalização e publicização dos princípios reguladores que dão legitimidade e buscam garantir a normalização. Esse esforço pode ser encarado como um gesto de deslegitimação institucional da emergência de novas práticas midiáticas, propiciadas pela era digital, mas também como uma tentativa de estabilização da definição de jornalismo. Para o Grupo Globo, o jornalismo seria praticado por qualquer veículo cujo propósito seja o de produzir conhecimento, diferentemente das mídias que desejam convencer ou defender uma causa:

Um está na órbita do conhecimento; o outro, da luta políticoideológica. Um jornal de um partido político, por exemplo, não deixa de ser um jornal, mas não pratica jornalismo, não como aqui 


\begin{abstract}
definido: noticia os fatos, analisa-os, opina, mas sempre por um prisma, sempre com um viés, o viés do partido. E sempre com um propósito: o de conquistar seguidores. Faz propaganda. Algo bem diverso de um jornal generalista de informação: este noticia os fatos, analisa-os, opina, mas com a intenção consciente de não ter um viés, de tentar traduzir a realidade, no limite das possibilidades, livre de prismas. Produz conhecimento. (Grupo Globo, 2010).
\end{abstract}

Há, nesse trecho, uma clara tentativa de manutenção da divisão moderna entre jornal e jornalismo. O último estaria associado a uma disciplina da verificação e conseguiria a proeza de "opinar sem ter um viés" ainda que "nos limites das possibilidades". Esse limite talvez corresponda a uma tentativa de suavizar o discurso da objetividade (como podemos perceber em outros trechos do documento), ainda que a relação epistemológica com a realidade aí defendida seja substancialmente a mesma. Longe de ser um caso isolado, o lançamento dos princípios editoriais do Grupo Globo reflete esse momento de transformação do -ismo jornalístico que, nesse artigo, podemos identificar em duas diferentes formas: 1) a autorreferenciação exaustiva de uma essência jornalística por parte de grupos midiáticos consolidados, 2) a emergência de novos atores individuais e em grupo que criticam duramente esses conglomerados, posicionando-se contra sua hegemonia e monopólio do fazer noticioso.

Outro caso emblemático no cenário jornalístico recente foi a reforma editorial da Folha de S. Paulo, em 2010. Curiosamente, 2010 é o ano em que a Folha perdeu, pela primeira vez desde 1986, o posto de jornal mais vendido no Brasil - dando lugar a um tablóide popular, o belo-horizontino Super Notícias. A reforma foi largamente divulgada por um conjunto de ações promovidas pelo jornal, entre elas, o caderno especial intitulado Novíssima! encartado na edição do dia da inauguração, e uma série de vídeos promocionais que anunciam: "Enquanto se discutia o futuro do jornal, a Folha fez o jornal do futuro" $(\mathrm{O}$ Jornal, 2010). Fazendo referência direta às discussões em torno do futuro do jornalismo impresso, a Folha anuncia o lançamento do seu "Jornal do Futuro", se colocando na vanguarda dos históricos processos de constituição da dita imprensa moderna brasileira. Tal gesto reinventa gestos semelhantes que foram performados diversas outras vezes na história, não apenas pela própria Folha, mas também por outros periódicos, como o próprio Diário Carioca e a Folha de 1975.

Nesse sentido, o material de divulgação da reforma promove uma atualização não apenas do lugar da Folha no cenário midiático, mas de importantes valores que supostamente orientam a história brasileira. No vídeo promocional, a reforma do diário é simbolizada, em primeiro lugar, pelas marcas 
de uma reforma que toma conta do "velho" edifício da Folha. A ele somos apresentados pela locução de Otavio Frias Filho, diretor de redação, jornalista na Folha desde 1975, ano em que seu pai inaugura uma de suas importantes reformas editoriais. Como diretor de redação, na década seguinte, Frias Filho encontra-se à frente da criação do Projeto Folha, plano que sistematiza as diretrizes editoriais do diário e que ainda hoje é pilar de sustentação dos seus discursos institucionais. No vídeo, Frias Filho é seguido por Sérgio Dávila, produtor executivo e diretor da atual reforma do diário. Dávila também inaugura sua participação no vídeo dizendo algo sobre aquele edifício: "O prédio velho da Folha, pra mim, é um motivo de orgulho. Porque é um jornal que tem noventa anos, então é um jornal sólido, de tradição, tem uma história; ao mesmo tempo é inquieto, é moderno, é nervoso" (O Jornal, 2010).

A reforma de 2010 inaugura a fusão de duas redações que funcionavam autonomamente, a do jornal diário impresso e a da até então chamada FolhaOnline. Como insistem vários entrevistados ao longo do vídeo, trata-se de uma oportunidade de afirmar que o trabalho da Folha se constitui em produzir notícias, e não em manter uma ou outra "plataforma". O termo "plataforma" é recorrente nos dizeres da reforma de 2010, e busca minimizar a importância do meio em função do seu conteúdo, ainda que vários de seus esforços surjam no sentido de tentar adaptar o impresso a parâmetros do mundo digital e em rede. Assim, por um lado, afirma-se que a qualidade das informações produzidas pela estrutura jornalística da Folha está acima de suas vitrines de exposição. Por outro, não se deixa de tentar reformular suas estratégias e formas de composição e exposição, ainda que sob a justificativa de que elas não alteram, ao cabo, sua "essência".

Essa série de discursos autorreferentes diz da consolidação de um modo hegemônico de se pensar o jornalismo. Dita concepção, se assenta em premissas de um paradigma linear, no qual um fato externo ao jornal deveria ser apurado de maneira objetiva pelo jornalista e transmitido ao público de maneira periódica. Ou seja, o jornalista possuía uma espécie de expertise em suas técnicas e o jornal um monopólio das ferramentas de produção e circulação das notícias. Como apontam Anderson, Bell e Shirk (2013), o jornalismo

era uma indústria que se mantinha em pé por coisas que em geral mantêm um setor em pé: a similitude de métodos entre um grupo relativamente pequeno e uniforme de empresas e a incapacidade de alguém de fora desse grupo de criar um produto competitivo. Essas condições não se cumprem mais (Anderson, Bell, Shirk, 2013, p.32). 
Nesse sentido, não apenas a dita imprensa de referência pode nos indicar as marcas de uma matriz jornalística em processo de recontextualização. Ao contrário, é justamente na disputa com outros agentes midiáticos que um diagrama de forças é constituído em torno da noção de jornalismo. Quando nos deparamos com os discursos autorreferentes proferidos pelos agentes "de fora" do grupo hegemônico no Brasil, podemos perceber de que modos e com que consequências a matriz em questão é tensionada.

\section{Novas reivindicações do -ismo}

Tomando parte ativa no questionamento do jornalismo hegemônico do Brasil e das práticas culturais e políticas a eles associadas, vêm se fortalecendo no país expressões das chamadas mídias alternativas. Destacamos aqui duas destas mídias: a Mídia Ninja e os Jornalistas Livres.

A Mídia Ninja ${ }^{3}$ é um produto colaborativo que realiza narrativas online sobre atos e manifestações políticas, que se destacou na cobertura dos protestos das chamadas jornadas de junho de 2013, e que se autodefine da seguinte maneira:

\footnotetext{
Uma rede de comunicadores que produzem e distribuem informação em movimento, agindo e comunicando. Apostamos na lógica colaborativa de criação e compartilhamento de conteúdos, característica da sociedade em rede, para realizar reportagens, documentários e investigações no Brasil e no mundo. Nossa pauta está onde a luta social e a articulação das transformações culturais, políticas, econômicas e ambientais se expressa. A Internet mudou o jornalismo e nós fazemos parte dessa transformação. Vivemos uma cultura peer-to-peer (P2P), que permite a troca de informações diretas entre as pessoas, sem a presença dos velhos intermediários.
}

Na definição, é evidente que a Mídia Ninja se insere no novo contexto midiático em que a internet possui um espaço cada vez mais relevante. Em primeiro lugar, os realizadores deste produto se definem enquanto rede, numa relação com a web e plataformas on-line. Além disso, convocam uma cultura colaborativa, peer-to-peer, argumentando que a sua forma de organização se estabelece com os participantes da rede sendo produtores e consumidores de conteúdo. Há ainda a crítica aos "velhos intermediários", que não seriam condizentes com a pretendida independência da narrativa que produzem.

O Jornalistas Livres (2017), por sua vez, foi criado em março de 2015, por iniciativa de um grupo de jornalistas de São Paulo, que se define como uma

3 Ninja é sigla para Narrativas Independentes, Jornalismo e Ação. 
"rede de coletivos originada na diversidade". Baseiam-se, como a Mídia Ninja, na convocação de uma cultura peer-to-peer. No seu manifesto de criação, o Jornalistas Livres, que tem um megafone como identidade visual, busca se articular a outras características que configuram parte da cultura digital no Brasil, dizendo se contrapor "à falsa unidade de pensamento e ação do jornalismo praticado pela mídia tradicional centralizada e centralizadora". Segundo eles, os jornalistas que compõem essa nova rede pensam com suas "próprias cabeças", reivindicando uma autonomia institucional que seria âncora da autenticidade do seu trabalho:“Somosnoss@sprópri@s patrões/patroas, somos noss@s própri@s empregad@s. Almejamos viver em liberdade e vivemos na busca incessante por liberdade".

A fim de referendar este discurso de liberdade - presente já no nome do grupo -, eles recorreram a uma forma de financiamento que também se utiliza das possibilidades tecnológicas da internet: o crowdfunding (financiamento colaborativo). Em troca de ajudar a financiar a sede e equipamentos dos Jornalistas Livres - que pode ser utilizada por qualquer jornalista - as pessoas convidadas a contribuir tiveram seus nomes inseridos no manifesto e receberam brindes (camisas, livros, adesivos, entre outros). Trata-se, com isso, de um tensionamento às formas de financiamento mais tradicionais da imprensa brasileira, baseada no anúncio de governos e empresas privadas.

Aqui, tanto os discursos citados anteriormente quanto a forma de financiamento e compartilhamento do ambiente de trabalho e dos equipamentos são alterações importantes no nível da institucionalidade. Ao se investir da alteração dos processos de produção, veiculação e consumo das reportagens, valores como a liberdade de expressão são reapropriados e utilizados como argumentos de crítica ao jornalismo hegemônico.

É interessante notar, também, que a forma de se expressar no manifesto promove uma aproximação com uma forma de grafia comum na internet, com a arroba complementando palavras que acolhem distintas possibilidades de gênero: "orientad@s", "noss@s", própri@s". Desta maneira, o Jornalistas Livres marcam uma postura cujos questionamentos vão além de uma normatividade estritamente jornalística. Esse atrelamento fica ainda mais nítido na forma de organização do site do Jornalistas Livres, em que eles preveem as seguintes editorias a serem cobertas pelo coletivo de jornalistas: política, economia, saúde, negros, feminismo, educação, Rio Doce, índios e LGBT (Lésbicas, Gays, Bissexuais, Travestis, Transexuais e Transgêneros). Há, assim, uma mistura de editorias mais tradicionais do jornalismo brasileiro a outras que demonstram essas relações com identidades de minorias. Tal aspecto ganha lastro no seguinte trecho do manifesto: 
\#Jornalistas Livres nos horrorizamos diante de quaisquer preconceitos e vivemos para combatê-los. Somos mulheres, homens, cisgêneros, transexuais,não-binári@s,negr@s, branc@s, amarel@s, mestiç@s, indígenas, quilombolas, caiçaras, lésbicas, gays, homossexuais, bissexuais, heterossexuais, polissexuais, assexuais, religios@s, ateus, agnostic@s, pobres, remediad@s,ric@s, velh@s, jovens, de meia-idade, experientes, novat@s, alun@s, professores, arraigad@s, nômades, cigan@s, INDECIS@S (Oximity, 2017).

Assim, nas definições da Mídia Ninja e do Jornalistas Livres, pode-se notar que não há uma crença no jornalismo como processo isento ou imparcial, característica geral da retórica hegemônica do jornalismo no Brasil, que caracterizamos sob a matriz cultural do -ismo. Em vez disso, eles se oferecem de maneira explicitamente engajadas com os movimentos contra-hegemônicos no país, fazendo coincidir o investimento político com o questionamento institucional da matriz moderna do jornalismo.

Nos dois casos, é perceptível que a matriz jornalística em questão, encarnada nos discursos contra-hegemônicos como a "mídia tradicional", é o lugar de referência do que é jornalismo para estes novos veículos, ainda que seja para disputá-los em alguns momentos ou, em outros, reiterá-los. Ao passo em que questionam o jornalismo comercial, recorrem reiteradamente ao discurso de que fazem jornalismo, e de que são, de fato, jornalistas a fazerem estas coberturas. Além disso, utilizam, como no caso dos Jornalistas Livres, editorias clássicas do jornalismo moderno, tal qual economia e política, que são evocadas como garantidoras da existência de um jornalismo voltado para o interesse público. Reiteram, desta maneira, valores, práticas e espaços que têm sido afirmados como lugares importantes na construção do ismo. Isso fica explícito no seguinte trecho do quem somos do site dos Jornalistas Livres, em que eles apelam para certo "espírito jornalístico", "humano, humanizado e humanizador":

\#JornalistasLivres nos opomos aos estratagemas da tradicional indústria jornalística (multi)nacional, que, antidemocrática por natureza, despreza o espírito jornalístico em favor de maldisfarçados interesses empresariais e ideológicos, comerciais e privados, corporativos e corporativistas. [...]\#JornalistasLivres produzimos REPORTAGEM. Lamentamos o confinamento a que a indústria midiática relegou o mais nobre dos gêneros jornalísticos e trabalhamos para reduzir o abismo de desequilíbrio. A matériaprima de nossas reportagens é HUMANA. Almejamos um jornalismo humano, humanizado e humanizador[...] (Jornalistas Livres, 2017).

Ainda neste sentido, salientamos, sobre a Mídia Ninja, que, com suas transmissões realizadas em plano-sequência,"uma forma de filmagem codificada 
pelo gênero televisivo em coberturas continuadas" (Ferreira, 2016), acaba por reforçar o discurso que apontamos no início deste artigo, ao sugerir, em suas práticas, formas neutras de apreensão da realidade, ainda que fique evidente que também eles externam os seus pontos de vista, "se aproximando com o que está sendo narrado, relacionando-se a uma tendência do telejornalismo brasileiro" (Ferreira, 2016).

Assim, ambos os produtos que disputam sentidos do jornalismo recorrem a marcas e valores que o configuram de forma hegemônica, como a pretensão de apreender a realidade, de atender o interesse público. Fazem isso, entretanto, reapropriando-se dos discursos do ismo, ao defender que todos podem ser jornalistas e que os melhores jornalistas são os ninjas - que constroem narrativas independentes - ou os livres, dos interesses dos grupos identificados por eles como adversários. Este tipo de posição e construção narrativa sobre si mesmo explica em parte o sucesso que estes veículos têm nas redes sociais. Na semana do dia 08 de setembro de 2016, foi divulgada a informação que a Mídia Ninja superou mídias noticiosas como Estado de São Paulo, Folha de S. Paulo e O Globo, em número de engajamento no Facebook (Redação Portal Imprensa, 2016).

Por fim, é importante notar que as questões institucionais ganham novos políticos mais evidentes na medida em que o contexto da "crise" e o do golpe parlamentar se entrecruzam. Tais agentes da mídia alternativa buscam denunciar o golpe, acusando os veículos tradicionais de não produzir uma narrativa fidedigna à realidade do país. Eles clamam, então, pela necessidade de produção e consumo de outras narrativas possíveis e mais reais, como se eles mesmos não estivessem recorrendo a práticas que criticam. É notória a proximidade desses veículos com grupo políticos partidários de esquerda, o Partido dos Trabalhadores (PT) e o Partido Socialismo e Liberdade (PSOL), sendo a parcialidade que criticam no jornalismo hegemônico mais uma característica a ser reproduzida por eles.

Nota-se, assim, que a revisão e atualização da matriz dominante do jornalismo passam sempre necessariamente pela recontextualização de certos valores à luz das questões e disputas em prática nos contextos historicamente constituídos. E se tais valores são muito mais mutáveis e contraditórios do que fazem parecer os discursos deontológicos do jornalismo, eles surgem muito mais complexos quando apreendidos processualmente nas ações, sejam elas hegemônicas ou contra-hegemônicas, que constituem e transformam constantemente essa matriz do jornalismo moderno. 


\section{Considerações finais}

Como vimos, os valores e práticas que configuram o que indicamos como o ismo no campo jornalístico tem como importantes matrizes culturais discursos, formatos e lógicas produtivas que remontam pelo menos à década de 1950 no Brasil. Além disso, em um rápido esforço de historicização, é possível perceber em que termos ela é devedora de outros processos que se instituem nos EUA nas primeiras décadas do século XX. Mas menos do que promover um mapeamento histórico desses processos, o que devemos salientar aqui é a nossa aposta interpretativa dupla, que tem na historicidade dos fenômenos comunicacionais seu lugar de sustentação.

Em primeiro lugar, podemos perceber que alguns valores historicamente constituídos são configuradores das maneiras de conceber e fazer jornalismo. Eles fazem parte, assim, da estruturação de parâmetros normativos que regulam práticas e discursos contemporâneos na cultura midiática. Na esteira de Martín-Barbero (2008), podemos afirmar que estes discursos em torno do ismo constituem institucionalidades sobre o jornalismo, com valores e práticas que são matrizes culturais que regulam o campo e são acionados pela reiteração nos discursos dominantes dos jornais de referência, ou mesmo em veículos que se apresentam como alternativos ao modo hegemônico de fazer jornalismo. Percebemos isso com discursos que ressaltam certo jornalismo "humanizado" ou na utilização de certos modos de fazer, tais qual o plano-sequência na construção da narrativa jornalística.

Entretanto, como mostramos, esses novos agentes disputam algumas das práticas hegemônicas atualizando esta matriz por meio da crítica, da utilização de outras formas de engajamento do público - passando pelo próprio financiamento via crowdfunding - e da reivindicação de sua legitimidade no campo jornalístico. Os valores do jornalismo são, assim, em segundo lugar, constantemente reinventados culturalmente pelas práticas e discursos que emergem historicamente. Tal processo implica em perceber que a recontextualização de uma matriz cultural midiática se dá não pela simples adaptação de textos fundadores para circunstâncias diversas daquelas "originais", mas, no limite, da reinvenção da matriz na atualidade.

Assim, neste trabalho de ativo de recontextualização do -ismo nas disputas midiáticas, é importante compreender o gesto de referencialidade que se instaura nas relações históricas do jornalismo. Ainda que o discurso da crise esteja ancorado no passado e em uma lógica teleológica da história, o novo contexto acaba por criar suas próprias formas de conceber o passado pelas demandas de reapropriação no presente. O que observamos, nesse sentido, é uma disputa por uma referencialidade que, em vez de ser resgatada da história, 
é produzida e oferecida para a história. Como em qualquer luta pela hegemonia, os embates por um lugar no jornalismo são também, em sentido forte, disputas de jornais pela própria história, seu passado e seu futuro.

\section{Referências}

ALBUQUERQUE, Afonso de. A modernização autoritária do jornalismo brasileiro. Revista Alceu, Rio de Janeiro, v. 10, n. 20, p. 100-115, jan./jun. 2010.

ALBUQUERQUE, Afonso de; GAGLIARDI, Juliana.The copy desk and the dilemmas of the institutionalization of the "modern journalism" in Brazil. Journalism Studies, London, v. 12, p. 80-91, 2011. https://doi.org/10.1080/1461670X.2010.511956

ALCIDES, Jota. $O$ papel do jornal. Observatório da Imprensa, São Paulo, n. 841, 10 mar. 2015. Disponível em: http://observatoriodaimprensa.com.br/imprensa-emquestao/ ed841 o papel do jornal Acesso em: mai. 2015.

ALMIRON, Núria. Journalism in crisis: corporate media and financialization. Cresskill: Hampton Press, 2010.

ANDERSON, Christopher. W.; BELL, Emily; SHIRKY, Clay. Jornalismo pós-industrial. Revista de Jornalismo da ESPM, São Paulo, n. 5, p. 30-89, abr./jun. 2013. Disponível em: http://www.espm.br/download/2012 revista jornalismo/ Revista de Jornalismo ESPM 5/files/assets/common/downloads/REVISTA 5. pdf. Acesso em: 1 dez. 2016.

BABREU, Alzira Alves. A modernização da imprensa: 1970-2000. Rio de Janeiro: Jorge Zahar, 2002.

BARBOSA, Marialva. História cultural da imprensa: Brasil, 1900-2000. Rio de Janeiro: Mauad X, 2007.

CHALABY, Jean K. Journalism as an anglo-american invention: a comparison of the development of french and anglo-american journalism, 1830s-1920s. European Journal of Communication, Thousand Oaks, v. 11, n. 3, p. 303-326, set. 1996. https://doi.org/10.1177/0267323196011003002

DAHLGREN, Peter. The troubling evolution of journalism. In: ZELIZER, Barbie (org.). The changing faces of journalism: tabloidization, technology and truthyness. New York: Routledge, p. 146-160, 2009.

DAHLGREN, Peter. Trazando la evolución del periodismo: el horizonte de la democracia. Revista Iberoamericana de Comunicación Infoamérica, Málaga, n. 2, p. 2138, jan./abr. 2010

DINES, Alberto. 0 papel do jornal: tendências da comunicação e do jornalismo no mundoem crise. Rio de Janeiro: Artenova, 1974. 
FERREIRA, Thiago. Mídia Ninja e juventude: corpos e afetos na disputa política e nas narrativas audiovisuais. In: JESUS, Eduardo; TRINDADE, Eneus; JANOTTI Jr., Jéder; ROXO, Marco (org.). Reinvenção comunicacional da política: modos de habitar e desabitar o século XXI. Salvador: EDUFBA; Brasília: Compós, p. 129145, 2016.

FULLER, Jack. What is happening to news: the information explosion and the crisis in journalism. Chicago: University of Chicago Press, 2010. https://doi.org/10.7208/ chicago/9780226268996.001.0001

GILLMOR, Dan. The end of objectivity. 20 Jan. 2005. Disponível em: http://dangillmor. typepad.com/dan gillmor on grassroots/2005/01/the end of obje.html. Acesso em: 4 dez. 2016.

GOMES, Itania e outros. Porque o jornalismo faz rir: matrizes midiáticas do programa Sensacionalista, do Multishow. In: LISBOA FILHO, Flavi Ferreira; BAPTISTA, Maria Manuel (org.). Estudos culturais e interfaces: objetos, metodologias e desenhos de investigação. Universidade de Aveiro, Programa Doutoral em Estudos Culturais. Santa Maria: UFSM, Programa de Pós-Graduação em Comunicação, 2016.

GROSSBERG, Lawrence. Cultural studies in the future tense. Durham and London: Duke University Press, 2010.

GRUPO O Globo. Disponível em: http://g1.globo.com/principios-editoriais-do-grupoglobo.html. Acesso em: 30 abr. 2010.

JÁCOME, P.; LEAL, B. S. ; MANNA, Nuno . Mudar para permanecer o mesmo: marcas de um discurso de autolegitimação jornalística na história. Galáxia (São Paulo. Online), v. 1, p. 149-162, 2017.

JOBIM, Danton. French and U.S. influences upon the latinamerican press. Journalism Quarterly, v.31.n. 1, p.61-66, dez. 1954.

JORNALISTAS LIVRES. Quem Somos. Disponível em: https://jornalistaslivres.org/ quem-somos. Acesso em: 06 de fev. 2017.

KAPLAN, Richard Lee. Politics and the American Press: the rise of objectivity, 18651920. Cambridge: Cambridge University Press, 2002.

.The origins of objectivity in american journalism. In: ALLAN, Stuart (org.). The Routledge Companion to News and Journalism. London: Routledge, 2010. p. 25-37.

KOVACH, Bill; ROSENSTIEL, Tom. Os elementos do jornalismo: o que os jornalistas devem saber e o público exigir. 2. ed. São Paulo: Geração Editorial, 2004.

LAGE, Nilson Lemos; FARIA, Tales; RODRIGUES, Sérgio. Diário Carioca: o primeiro degrau 
para a modernidade. Estudos em Jornalismo e Mídia: Florianópolis, v. 1, n. 1, p. 132-144, 2004.

LISBOA FILHO, Flavi Ferreira; BAPTISTA, Maria Manuel (org.). Estudos culturais e interfaces: objetos, metodologias e desenhos de investigação. Aveiro: Universidade de Aveiro, Programa Doutoral em Estudos Culturais. Santa Maria: UFSM, Programa de Pós-Graduação em Comunicação, 2016.

MARTÍN-BARBERO, Jesús. Dos meios às mediações: comunicação, cultura e hegemonia. Rio de Janeiro: UFRJ, 2008.

MÍDIA NINJA. Quem somos. Disponível em: https://ninja.oximity.com/partner/ninja/ about. Acesso em 06 de fev. 2017.

MOTTA, Luiz Gonzaga. Crise nos paradigmas do jornalismo. Observatório da Imprensa, São Paulo, 21 ago. 2002. Disponível em: http://www.observatoriodaimprensa. com.br/artigos/da210820022.htm. Acesso em: 01 fev. 2014.

NERONE, John. The historical roots of the normative model of journalism. Journalism, Thousand Oaks, v.14, n.4, p. 446-458, 2013.

.The journalism tradition. In: EADIE, Wilian F. 21st Century Communication: a reference handbook. Thousand Oaks: Sage, p. 31-38, 2009.

NOBLAT, Ricardo. A arte de fazer um jornal diário. São Paulo: Contexto, 2008.

O JORNAL do futuro. Direção Fernando Andrade. Trilha, Edição e Mixagem de Som: B, A, START!. São Paulo: Spray Filmes, 2010. (18 min), som., color., arquivo digital.

OXIMITY. Perfil Mídia Ninja no Oximity. Disponível em: https://ninja.oximity.com/ partner/ninja/about. Acesso em: 6 fev. 2017.

PORTAL IMPRENSA. Mídia Ninja ultrapassa grandes veículos em engajamento no Facebook. Disponívelem: http://portalimprensa.com.br/noticias/brasil/78276/ midia+ninja+ultrapassa+grandes+veiculos+em+engajamento+no+facebook. Acesso em: 26 abr. 2017.

REDAÇÃO PORTAL IMPRENSA. Mídia Ninja ultrapassa grandes veículos em engajamento no Facebook. 9 set. 2016. Disponível em: http://portalimprensa.com.br/noticias/brasil/78276/ midia+ninja+ultrapassa+grandes+veiculos+em+engajamento+no+facebook. Acesso em: 26 abr. 2017.

RIBEIRO, Ana Paula Goulart. Imprensa e história no Rio de Janeiro dos anos 50. Rio de Janeiro: E-papers, 2007.

ROSEN, Jay. Para além da objectividade. Revista de Comunicação e Linguagens, Lisboa, n. 27, 2003. 
SANT'ANNA, Lourival. O destino do jornal: a Folha de S. Paulo, O Globo e O Estado de São Paulo na sociedade da informação. Rio de Janeiro: Record, 2008.

SCHILLER, Dan. Objectivity and the news: the public and the rise of commercial journalism. Philadelphia: University of Pennsylvania Press, 1981.

SCHLESINGER, Philip. Is there a crisis in british journalism? Media, Culture \& Society, London,v. 28, n. 2, p. 299-307, mar., 2006.

SCHUDSON, Michael. Descobrindo a notícia. Uma história social dos jornais nos Estados Unidos. Petrópolis: Vozes, 2010.

.The objectivity norm in american journalism. Journalism, Thousand Oaks, v. 2, n. 2, p.149-170, 2001.

STARR, Paul. An unexpected crisis: the news media in postindustrial democracies. International Journal of Press/Politics, v. 17, n. 2, p. 1-9, fev., 2012.

YOUNG, Sally. The Journalism "crisis": is Australia immune or just ahead of its time? Journalism Studies, London, v. 11, n. 4, p. 610-624, mar. 2010. https://doi. org/10.1080/14616701003638517

ZELIZER, Barbie. Public spheres, imagined communities, and the underdeveloped historicalunderstanding of journalism. In: ZELIZER, Barbie (org.). Explorations in communicationand history. New York: Routledge, p. 181-189, 2008.

ZELIZER, Barbie. Why journalism's changing faces matter. In: ZELIZER, Barbie (org.). The changing faces of journalism: tabloidization, technology and truthyness. New York: Routledge, p. 1-10, 2009.

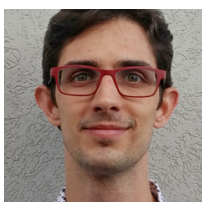

Nuno Manna <nunomanna@gmail.com>

Faculdade de Comunicação da Universidade Federal da Bahia (UFBA)

Rua Barão de Jeremoabo, $\mathrm{s} / \mathrm{n}^{\circ}$ - Ondina

40170-115 - Salvador (BA) - Brasil

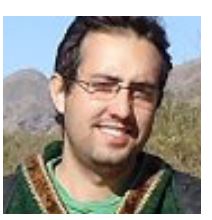

Phellipy Jácome <phellipyjacome@gmail.com>

Instituto de Ciências Sociais Aplicadas da Universidade Federal de Ouro Preto (UFOP)

Rua do Catete, 166, Centro

35420-000 - Mariana (MG) - Brasil

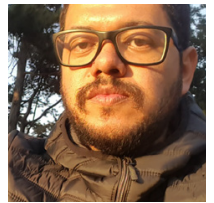

Thiago Ferreira <thiagoemanoel87@gmail.com>

PPGCom da Universidade Federal da Bahia (Póscom-UFBA)

Rua Barão de Jeremoabo, $\mathrm{s} / \mathrm{n}^{\circ}$ - Ondina

40170-115 - Salvador (BA) - Brasil 